\title{
A new approach to improving efficiency of gas-lift wells in the conditions of the formation of organic wax deposits in the Dragon field
}

\author{
Van Thang Nguyen ${ }^{1}\left[\right.$ ] Mikhail Konstantinovich Rogachev ${ }^{1} \cdot$ Aleksandr Nikolaevich Aleksandrov $^{1}$
}

Received: 25 April 2020 / Accepted: 5 August 2020 / Published online: 14 August 2020

(c) The Author(s) 2020

\begin{abstract}
Gas-lift is one of the artificial methods in which gas is injected down the production casing-tubing annulus and enters the production tubing through a number of gas-lift valves. During the production of a gas-lift well, the injected compressed gas might cause changes in pressure, temperature as well as fluid composition. When the temperature of the oil falls below the wax appearance temperature, it leads to the formation of organic wax deposits. Wax precipitation in well tubing and processing equipment might lead to dramatic reduction in production, equipment failures, loss of storage and transport capacity, and loss of efficiency. This paper presents a detailed study of wax formation in a gas-lift well. Taking into account changes in the oil component composition during gas injection, the depth of wax formation has been determined by applying a highly accurate developed algorithm. The optimal operating regime of the gas-lift well has been determined using a compositional multiphase model.
\end{abstract}

Keywords High-wax oil · Operation of gas-lift wells · Wax appearance temperature · Dispersed oil system

\section{Introduction}

Gas-lift is a simple reliable artificial lift method that is commonly used in offshore oil field development (Fleyfel et al. 2004; White et al. 2018; Shedid and Yakoot 2016; Feder 2019). It is considered as one of the industry's first and foremost choices to develop low-pressure oil fields, with the proviso that there is a sufficient supply of injection gas. The compressed gas is injected down the production casing-tubing annulus, entering the tubing through the gas-lift valves. Sevic and Grubac (2017) show that as the gas enters the tubing, it forms bubbles and lightens the oil by reducing fluid density as well as lowering the flowing bottom hole pressure, creating a depression that allows the fluid to flow into the wellbore.

Van Thang Nguyen

thangluongsp92@gmail.com

1 Department of Oil and Gas Field Development and Operation, Oil and Gas Faculty, Saint Petersburg Mining University, Saint Petersburg, Russia 199106
Flow assurance in oil and gas production is regarded as the ability to produce fluids economically, from the reservoir to the surface over the life of a field and in any conditions.

The gas-lift application can affect flow assurance issues. A principal challenge in many oil industry production situations is paraffin wax. Up to $80 \%$ of the world's oil suffers when wax precipitates out and solidifies in formation pores and fluid flow channels, at the wellbore, on the sidewalls of wells, in the tubing, casings, pump strings, and in processing systems. Wax precipitation may change the flow behavior of the crude oil from Newtonian to non-Newtonian which leads to higher liquid viscosity and consequently leads an increase in energy consumption for pumping as well as a decrease in pumping capacity (Zheng et al. 2016; Zheng et al. 2017; Drozdov and Gorbyleva 2019; Leontaritis et al. 1998; Gabov et al. 2019). Furthermore, wax deposition in well tubing and processing equipment may lead to more frequent shutdowns and operational hazards and as a result cause dramatic reduction in production, equipment failures, loss of storage and transport capacity, and loss of efficiency.

Wax is composed of n-paraffin, i-paraffin, and c-paraffin with carbon numbers from 18 to 65 (Berne-Allen and Work 1938; Lake et al. 2006; White et al. 2018; Rogachev and Strizhnev 2006). Fadairo et al. (2010) showed that waxes

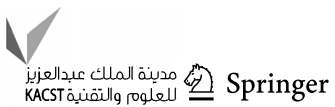


are precipitated as solids with the changing thermodynamic equilibrium when the oil temperature cools down lower than the wax appearance temperature (WAT). Berne-Allen suggested that the WAT is one of the main factors, which needs to be taken into account when developing preventative strategies for handling wax deposition in oil wells. Besides, the operating pressure in the wellbore also influences the formation of the organic wax deposits through its effects on the dissolved gas. The dissolved gas can be perceived as a solvent for organic deposits. Thus, as the gas starts being released from liquid form the probability of wax formation increases (Pedersen et al. 1989; Weingarten and Euchner 1988; Hansen et al. 1988; Decker and Sutton 2018).

The availability of accurate, reliable mathematical models of the gas-lift process is vital for the design and operation of a gas-lift system. Conventional models of continuous gaslift processes applied a black-oil treatment of the hydrocarbon fluids (Carroll et al. 1990; Schou et al. 1991; Mydland et al. 2020; Du et al. 2018; Coutinho et al. 2017; Zhao et al. 2017). Those models are unreliable due to the multiphase flow regime of the oil and gas mixture and consequently, the pressure drop in the wellbore is highly composition dependent. As the mixture flows up the wellbore, the changes in the flow regime are of paramount importance for developing a reliable continuous gas-lift model which is the compositional multiphase model. There are several programs such as PIPESIM, Aspen HYSYS, and OLGA which are developed specifically for simulation and analysis of the complex multiphase system (Mahmudi and Taghi Sadeghi 2013; Aslanov et al. 2019; Aleksandrov et al. 2019).

The WAT is contingent on the composition of the waxcontaining fluid and consequently on the amount of gas dissolved in the oil (Lira-Galeana et al. 1996; Ravindran and Horne 1993). During the production of a gas-lift well, the presence of multiple phases considerably complicates the study of wax precipitation process given the fact that the properties of each fluid present, as well as the compressed gas injected into production tubing must be taken into account. Furthermore, the interactions between each phase must be considered. Mixture properties must be used, and accordingly, the gas volume fractions throughout the pipe need to be determined. Won et al. (1986) and Zhao et al. (2017) show that the WAT prediction methods are based on the thermodynamic phase equilibrium relations. In these methods, the fugacities must be counted. Moreover, the WATs are the same for a pure substance, whereas it is vastly different for a mixture. The well-known methods to study the wax formation process during the production in a gas-lift well have overlooked the effects of the compressed injected gas on the WAT subsequently it leads to a significant error and creates many operational hazards for the development of the oil field. Hence, it is crucial to develop a highly accurate mathematical model to study the wax formation process during the production of a gas-lift well in order to remediate the occurrence of the wax deposits and as a result improve the efficiency of the gas-lift well production.

The novelty of this paper is to provide a detailed study of the wax formation process in a gas-lift well. Taking into account changes in the oil component composition during gas injection, the depth of wax formation has been determined by utilizing a developed algorithm. The optimal operating regime of a gas-lift well (flow rate and the injection pressure of produced gas) has been determined using the compositional multiphase model.

\section{Materials and methods}

In this work, we used the results of laboratory studies of the physicochemical properties of the high-wax oil in the Dragon field in Vietnam, as well as the results from modeling the movement of the specified high-wax oil along the wellbore of a gas-lift well through the Schlumberger PIPESIM software package.

\section{Results and discussion}

\section{Initial data}

The object of the study is a production gas-lift well operating under conditions of intensive organic wax deposit formation in the Dragon field.

The Dragon field is located off the southern coast of Vietnam, $120 \mathrm{~km}$ from Vung Tau city. Igneous and metamorphic rocks of the basement and sedimentary deposits represent the geological cross section of Dragon field. The pressure for the basement reservoir is $19.4 \mathrm{MPa}$, and the current reservoir temperature is $137{ }^{\circ} \mathrm{C}$. The pressure at the bubble point is

Table 1 Physical and chemical properties of degassed oil from the basement formation in Dragon field

\begin{tabular}{lc}
\hline Main properties & Value \\
\hline Density at $20{ }^{\circ} \mathrm{C}\left(\mathrm{kg} / \mathrm{m}^{3}\right)$ & 840 \\
The pour point $\left({ }^{\circ} \mathrm{C}\right)$ & 32.5 \\
WAT $\left({ }^{\circ} \mathrm{C}\right)$ & 49.5 \\
Volumetric coefficient & \\
At the reservoir condition & 1.35 \\
At the bubble point & 1.41 \\
Viscosity at $50{ }^{\circ} \mathrm{C}\left(\mathrm{mm}^{2} / \mathrm{s}\right)$ & 6.77 \\
Viscosity at $70{ }^{\circ} \mathrm{C}\left(\mathrm{mm}^{2} / \mathrm{s}\right)$ & 4.44 \\
Hydrocarbon group composition $(\%$ by mass) & \\
Wax content $(\mathrm{wt} \%)$ & 24.3 \\
Asphaltene and resin content $(\mathrm{wt} \%)$ & 3.29 \\
\hline
\end{tabular}


13.8 MPa. Physicochemical properties of degassed oil of the basement formation of the Dragon field are presented in Table 1.

These oils of the basement formation can be described as belonging to the high-wax type (wax content is $24.3 \%$ by mass) and are resinous with a high pour point.

\section{Method to determine changes in the component composition of oil in a gas-lift well during the injection of produced petroleum gas}

The WAT is subject to fluid composition and consequently, the amount of gas dissolved in the oil. During the production of a gas-lift well, the presence of multiple phases considerably complicates the study of wax precipitation given the fact that the properties of the fluid as well as the compressed gas injected into production tubing must be taken into account. Furthermore, the interactions between each phase must be considered. Mixture properties must be used, and accordingly, the gas volume fractions throughout the pipe need to be determined. Moreover, The WAT prediction methods are based on thermodynamic phase equilibrium relations. In these methods, the fugacities must be counted. Furthermore, the WATs are the same for a pure substance, whereas it is vastly different for a mixture. Well-known methods to study the wax precipitation process during the production in a gas-lift well have overlooked the effects of compressed injected gas on the WAT which subsequently leads to a significant error and creates many operational hazards for the development of oil field. Hence, it is crucial to develop a highly accurate mathematical model to study the wax formation process during the production of a gas-lift well in order to remediate the occurrence of wax deposits and as a result improve the efficiency of the gas-lift well production. The main properties of reservoir oil and injected produced gas are given in Table 2.

If the data of the component composition of the reservoir fluid are not divided into separate hydrocarbon components, then it is necessary to redistribute these components into separate pseudo-components according to the Katz method:

$\sum_{n=7}^{n+} z_{n}=z_{C_{7+}}$

$z_{n}=1.269831 z_{C_{7_{+}}} \exp (-0,26721 n)+0.0060884 z_{C_{7_{+}}}+10.425 \cdot 10^{-6}$

$M_{n+}=\frac{z_{C_{7+}} M_{C_{7+}}-\sum_{n=7}^{n+-1}\left[z_{n} M_{n}\right]}{z_{n+}}$
Table 2 Blend composition of the reservoir oil and injected produced gas (mole fraction, \%)

\begin{tabular}{|c|c|c|}
\hline Chemical formula & Reservoir oil & $\begin{array}{l}\text { Injected } \\
\text { produced } \\
\text { gas }\end{array}$ \\
\hline $\mathrm{N}_{2}$ & 0.142 & 0.302 \\
\hline $\mathrm{CO}_{2}$ & 0.000 & 0.589 \\
\hline $\mathrm{CH}_{4}$ & 30.890 & 77.634 \\
\hline $\mathrm{C}_{2} \mathrm{H}_{6}$ & 8.661 & 10.851 \\
\hline $\mathrm{C}_{3} \mathrm{H}_{8}$ & 7.800 & 6.296 \\
\hline $\mathrm{i}-\mathrm{C}_{4} \mathrm{H}_{10}$ & 1.649 & 1.109 \\
\hline $\mathrm{n}-\mathrm{C}_{4} \mathrm{H}_{10}$ & 3.455 & 1.657 \\
\hline $\mathrm{i}-\mathrm{C}_{5} \mathrm{H}_{12}$ & 1.279 & 0.369 \\
\hline $\mathrm{n}-\mathrm{C}_{5} \mathrm{H}_{12}$ & 1.646 & 0.381 \\
\hline Pseudo- $\mathrm{C}_{6}$ & 3.008 & 0.297 \\
\hline Pseudo- $\mathrm{C}_{7}$ & - & 0.346 \\
\hline Pseudo- $\mathrm{C}_{8}$ & - & 0.062 \\
\hline Pseudo- $\mathrm{C}_{9}$ & - & 0.092 \\
\hline Pseudo- $\mathrm{C}_{10}$ & - & 0.011 \\
\hline Pseudo- $\mathrm{C}_{11}$ & - & 0.004 \\
\hline $\mathrm{C}_{12+}$ & - & - \\
\hline $\mathrm{C}_{7+}$ & 41.471 & 0.515 \\
\hline Molar mass. g/mol & 133 & 21.794 \\
\hline
\end{tabular}

$\gamma_{n+}=\frac{z_{n+} M_{n+}}{\frac{z_{C_{7+}} M_{C_{7+}}}{\gamma_{C_{7+}}}-\sum_{n=7}^{n+-1}\left[\frac{z_{n} M_{n}}{\gamma_{n}}\right]}$

where $z_{C_{7+}}$-mole fraction of $\mathrm{C}_{7+} ; n$-number of carbon atoms; $z_{n}$-mole fraction of the pseudo-component with $\mathrm{n}$ carbon atoms; $n+$ - the last hydrocarbon group in the $\mathrm{C}_{7+}$ group with $\mathrm{n}$ carbon atoms, for example $12+; M_{C_{7+}}, \gamma_{C_{7+}}$ -measured molecular weight and specific gravity of $\mathrm{C}_{7+}$; $M_{n}, \gamma_{n}$-molecular weight and specific gravity of the pseudocomponent with $\mathrm{n}$ carbon atoms.

Based on the known component composition of the hydrocarbon system at a specific pressure and temperature, calculations are performed to determine the molar fraction of the gas $n_{v}$ and liquid phases $n_{L}$ in the mixture, as well as the component composition of the liquid $x_{i}$ and gas phases $y_{i}$.

The flash calculation for determining $n_{L}, n_{v}, y_{i}$ and $x_{i}$ of a hydrocarbon mixture with a known general composition $z_{i}$ and characterized by a set of equilibrium relations $K_{i}$ are summarized in the following steps:

Step 1 Determination of the molar fraction of the gas phase $n_{v}$.

Suppose $n_{v}$ is determined by following the equation:

$n_{v}=\frac{M}{M+N}$ 
where $\quad M=\sum_{i}\left[z_{i}\left(K_{i}-\frac{1}{2}\right)\right]$

$N=\sum_{i}\left[z_{i}\left(\frac{1}{K_{i}+1}-\frac{1}{2}\right)\right]$

$f\left(n_{v}\right)=\sum_{i} \frac{z_{i}\left(K_{i}-1\right)}{n_{v}\left(K_{i}-1\right)+1}$

$f^{\prime}\left(n_{v}\right)=-\sum_{i} \frac{z_{i}\left(K_{i}-1\right)^{2}}{\left[n_{v}\left(K_{i}-1\right)+1\right]^{2}}$

$\left(n_{v}\right)_{n e w}=n_{v}-\frac{f\left(n_{v}\right)}{f^{\prime}\left(n_{v}\right)}$

where $\left(n_{v}\right)_{n e w}$-is the new value of $n_{v}$, which will be used for the next iteration. This procedure is repeated with the new $n_{v}$ value until convergence is reached:

$\left|\left(n_{v}\right)_{n e w}-n_{v}\right|<e p s$

where eps $=10^{-7}$

Step 2 Determination of the molar fraction of the liquid phase $n_{L}$ :

$n_{L}=1-n_{v}$

Equilibrium ratio (Standing correlation):

$K_{i}=\frac{1}{P} 10^{\left(a+c F_{i}\right)}$

$a=1.2+0.00045 P+15 \cdot 10^{-8} P^{2}$

$c=0.89+0.00017 P-3.5 \cdot 10^{-8} P^{2}$

Characterization parameters:

$F_{i}=b_{i}\left[\frac{1}{T_{b i}}-\frac{1}{T}\right]$

$b_{i}=\frac{\log \left(p_{c i} / 14.7\right)}{\left[\frac{1}{T_{b i}}-\frac{1}{T}\right]}$

where $T_{b i}, P_{c i}$-reference values of critical pressures and boiling points of $\mathrm{i}-\mathrm{component}$

Step 3 Determination of the component composition of the liquid phase $« x_{i} »$

Given $n_{v}$ and $n_{L}$, we calculate the composition of the liquid phase according to the following equation:
$x_{i}=\frac{z_{i}}{n_{L}+n_{v} K_{i}}$

Step 4 Determination of the component composition of the gas phase $\ll y_{i} »$ :

$y_{i}=x_{i} K_{i}$

When injecting the produced gas into a well with a specific gas rate $R_{g}$ and planned liquid flow rate $Q_{L}$, gas flow through the gas-lift valve is calculated using the following formula:

$V_{g}=R_{g} Q_{L} / 86400, m^{3} / c$

The number of moles of produced gas injected through the gas-lift valve is calculated with the formula:

$P V_{g}=z n_{g} R T$

where $z$-compressibility coefficient of the real gas, $z \approx 1$ (This parameter can be determined graphically from known reduced pressures and temperatures using the Standing-Katz plot); $n_{\mathrm{g}}$-moles of the injected produced gas; $P$ the pressure at the injection depth, atm; $V_{\mathrm{g}}$-volume of the injected gas, 1; $T$-Temperature at the injection depth, $\mathrm{K}$; $R$ - gas constant $(0,08211 \mathrm{~atm} / \mathrm{mol} \mathrm{K})$.

The temperature and pressure values for calculating the amount of injected gas are obtained from the results of the analysis of the $\mathrm{P}-\mathrm{T}$ profile through the PIPESIM program.

Step 5 Determination of the new component composition of the gas phase:

We receive $m$ - the ratio of moles of injected gas to moles of oil per unit time:

$y_{i}^{*}=\frac{y_{i(g)} m+y_{i} n_{v}}{\left(n_{v}+m\right)}$

where $y_{i}^{*}$ - the new component composition of the gas phase of $i$-component taking into account the injected produced gas; $y_{i(g)}$-component composition of the gas phase of $i$ component included in the injected produced gas. The calculation result is presented in Table 3 .

Using the obtained results, for which the change in the component composition of the gas-liquid mixture was calculated taking into account the influence of the injected produced gas, the change in the WAT was determined by using the Multiflash 6.1 software product (Table 4).

As a result of the analysis, it was observed that with a decrease in pressure along the wellbore, the WAT decreases. It can be explained that when the pressure drops below the bubble point the light ends start being released from the oil. The effect of changes in the component composition of the studied oil on the WAT, when dissolved gas started being released from the oil, is directly correlated with the results 


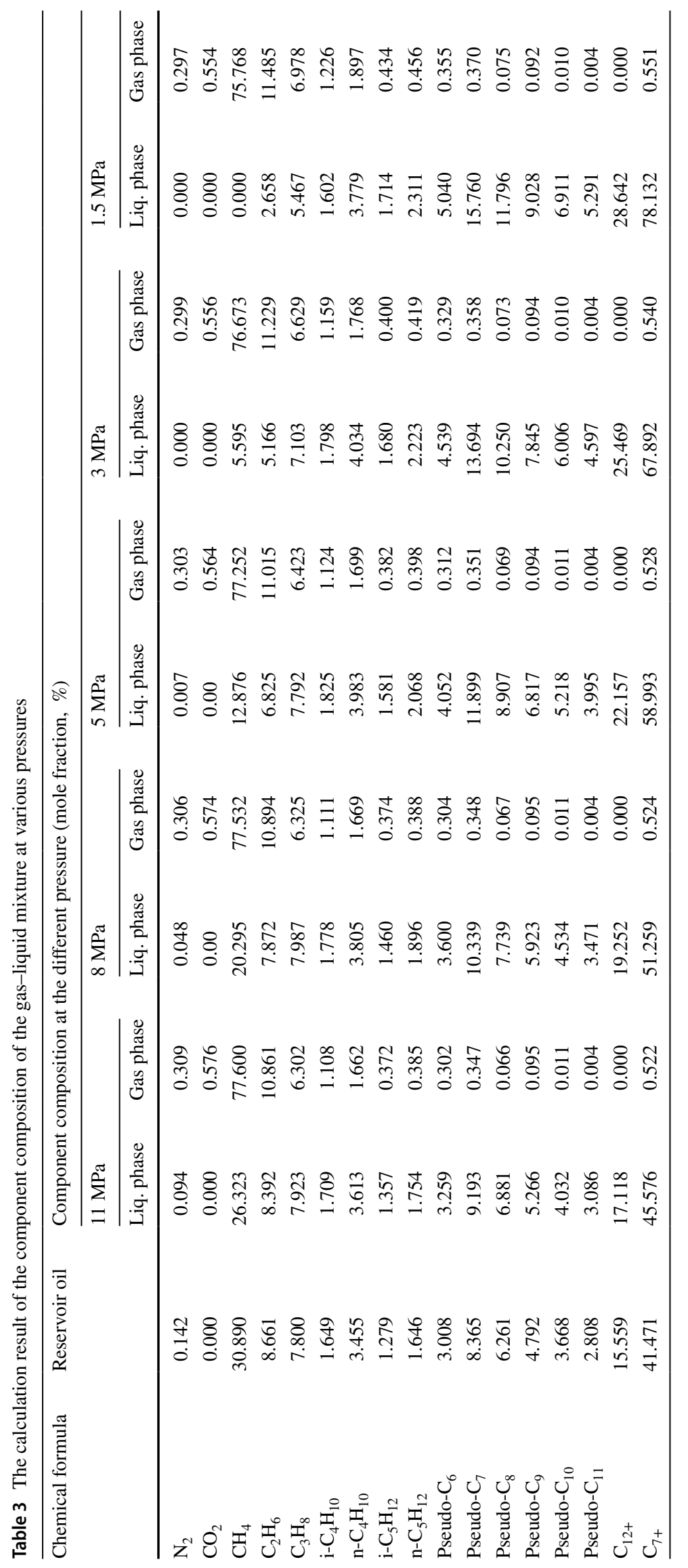


Table 4 Dependence of the wax appearance temperature on pressure

\begin{tabular}{lllcccc}
\hline Parameters & Value & \multicolumn{1}{l}{} \\
\hline Pressure $(\mathrm{MPa})$ & 13.8 & 11.0 & 8.0 & 5.0 & 3.0 & 1.5 \\
WAT $\left({ }^{\circ} \mathrm{C}\right)$ & 55.24 & 53.61 & 52.19 & 51.84 & 50.75 & 48.40 \\
\hline
\end{tabular}

Fig. 1 Dependence of the wax appearance temperature on pressure

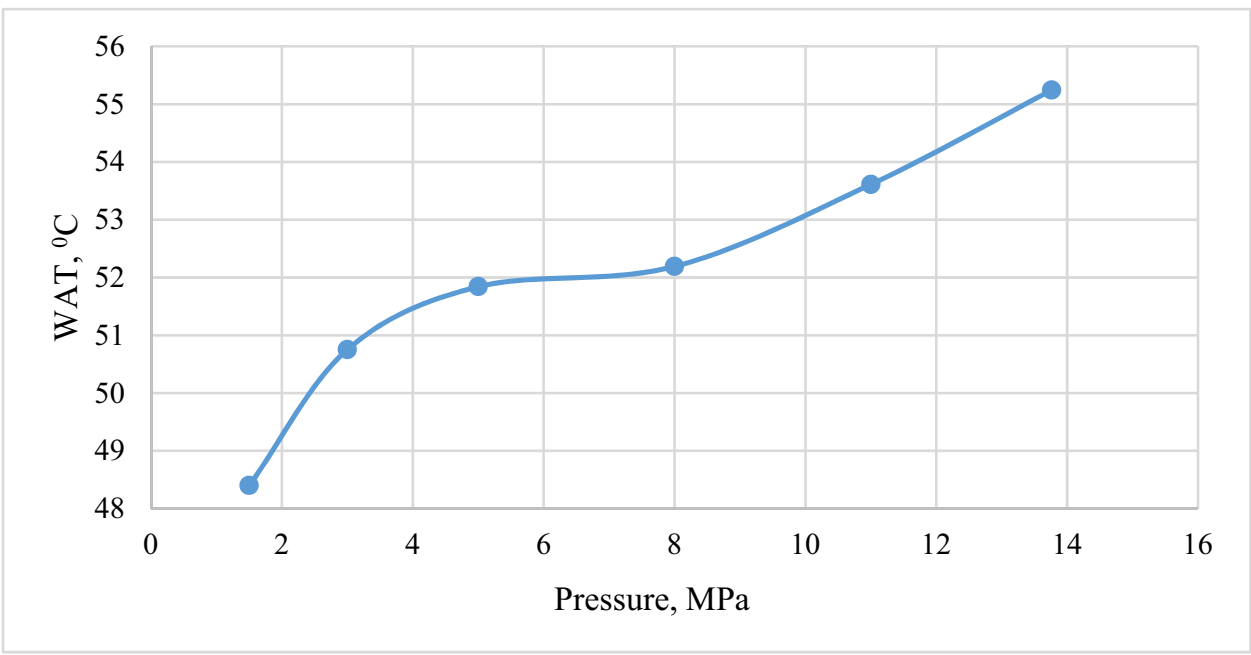

highlighted in the article (Aleksandrov et al. 2019). In this work, the authors have proven that an increase in the content of hydrocarbon gases (methane, ethane, and propane) might lead to an earlier transition of wax to the solid phase. The remaining hydrocarbon components from butane to nonane, on the contrary, act as solvents, slowing down the process of wax formation.

\section{Determination of the optimal operating regime of the gas-lift well}

The availability of accurate, reliable mathematical models of the gas-lift process is vital for the design and operation of a gas-lift system. The standard black-oil model is utilized in almost all prior studies of gas-lift well performance. Conventional studies assume that the hydrocarbon fluid system has a consistent composition. Therefore, most of the studies are performed based on the reduced black-oil model, in which it is alleged that the oil and gas phases are identified by oil and gas specific gravities that are regarded as constants during the production. In a standard black-oil model, PVT properties of hydrocarbon phases are described as a single function of pressure and temperature. Consequently, oil and gas properties such as viscosity, density, as well as specific volume are calculated by experimental correlations at a specific pressure and temperature (Mahmudi and Taghi Sadeghi 2013). Besides, the effect of compositions on pressure and temperature is omitted in the standard black-oil model. In reality, the effect of compositions on pressure profile and fluid flow properties should be considered when
Table 5 Well parameters

\begin{tabular}{ll}
\hline Parameter & Value \\
\hline Flow rate of the fluid at standard conditions $\left(\mathrm{m}^{3} / \mathrm{d}\right)$ & 103 \\
Productivity $\mathrm{Index}\left(\mathrm{m}^{3} / \mathrm{d}^{*} \mathrm{MPa}\right)$ & 1.548 \\
Gas/oil ratio $\left(\mathrm{m}^{3} / \mathrm{m}^{3}\right)$ & 139 \\
Surface pressure $(\mathrm{MPa})$ & 1.0 \\
Oil bubble point pressure $(\mathrm{MPa})$ & 13.7 \\
Reservoir pressure $(\mathrm{MPa})$ & 19.4 \\
Reservoir temperature $\left({ }^{\circ} \mathrm{C}\right)$ & 137 \\
Well depth $(\mathrm{m})$ & 4190 \\
Perforation depth $(\mathrm{m})$ & 4044 \\
Average angle of inclination of the well $(\mathrm{grad})$. & 2 \\
Internal diameter of the production string $(\mathrm{m})$ & 0.172 \\
Packer installation depth $(\mathrm{m})$ & 3893 \\
Internal diameter of tubing $(\mathrm{m})$ & 0.0573 \\
\hline
\end{tabular}

studying fluid behavior in a gas-lift well. There are several programs such as PIPESIM, Aspen HYSYS, and OLGA which are developed specifically for simulation and analysis of the complex multiphase system (Fig. 1).

The compositional multiphase model can be employed to predict the gas-lift well performance and select the optimal operating regime for the well the results of which is highly accurate compared to the conventional black-oil model. In this paper, we use the compositional multiphase high-wax model through the PIPESIM software product to study the performance of the gas-lift under conditions of intensive 


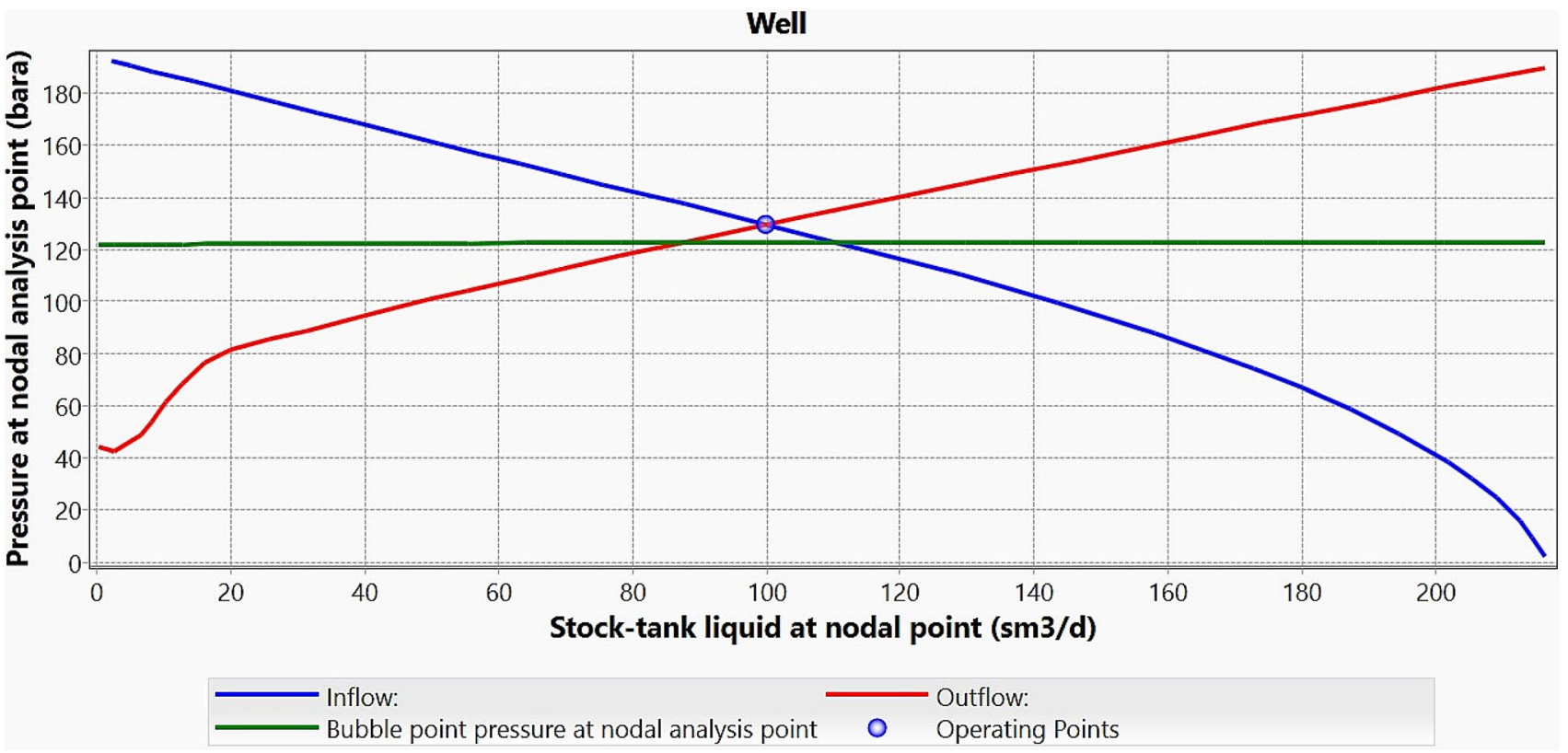

Fig. 2 Characteristics of the reservoir-well system of a gas-lift well

Table 6 The results from water cut effect analysis

\begin{tabular}{lll}
\hline Operating point & $\begin{array}{l}\text { Stock- tank Liquid at nodal } \\
\text { point }\left(\mathrm{m}^{3} / \mathrm{d}\right)\end{array}$ & $\mathrm{P}$ at NA (bara) \\
\hline WCUT $=5 \%$ & 96.96 & 131.36 \\
WCUT $=20 \%$ & 86.29 & 138.25 \\
WCUT $=35 \%$ & 74.59 & 145.81 \\
WCUT $=55 \%$ & 54.70 & 158.66 \\
WCUT $=65 \%$ & 74.18 & 146.07 \\
WCUT $=80 \%$ & 74.85 & 145.64 \\
WCUT $=90 \%$ & 71.39 & 147.87 \\
\hline
\end{tabular}

organic wax formation. The parameters of the basement formation wells are given in Table 5.

During production, the initial reservoir pressure declines to 19.4 MPa. To provide the well with sufficient energy to lift the fluid to the surface and achieve the planned flow rate $\left(100 \mathrm{~m}^{3} /\right.$ day $)$, it is necessary to use artificial lift methods for operating the well, in this case, the gas-lift method implemented. Figure 2 shows the characteristics of the reservoir-well system of a gas-lift well. The planned flow rate for liquid $\left(100 \mathrm{~m}^{3} /\right.$ day) is ensured with the injection pressure $10 \mathrm{MPa}$ and gas flow rate $20,000 \mathrm{~m}^{3} /$ day. The graph shows the line corresponding to the pressure of saturation of oil with gas (the bubble point).

Having created models of a gas-lift well and the flow of high-wax oil, we could simulate various hypothetical scenarios of well performances, such as pressure drops along the wellbore, an increase in water cut, etc., and subsequently, estimate the most effective options for the gas-lift welloperating regime. Table 6 and Fig. 3 show the effect of an increase in water cut on the change in the liquid flow rate of the gas-lift well.

It was perceived that with an increase in water cut to the phase inversion point (in the range from 50 to $60 \%$ water cut), an increase in the viscosity of the oil-water emulsion is observed, which leads to a decrease in the liquid flow rate of the gas-lift well. With a water cut of over $60 \%$, an increase in well production is obtained.

Using the system analysis function to evaluate the effect of changes in the gas rate of the injected produced gas on the liquid flow rate of the gas-lift well allows us to determine the effective regime of the well operation with an increase in water cut. Figure 4 shows the results of choosing the optimal operation regime of the gas-lift well during the production of water contained products.

Using results obtained by choosing the optimal regime of the gas-lift well during the production of water contained products, it was established that the liquid flow rate of the well increases with an increase in the gas injection rate to a point after which the liquid flow rate of the well plateaus (Table 7).

\section{Determination the depth of wax formation}

The wax appearance temperature in the gas-lift well is a function that depends on pressure, fluid temperature, oil 


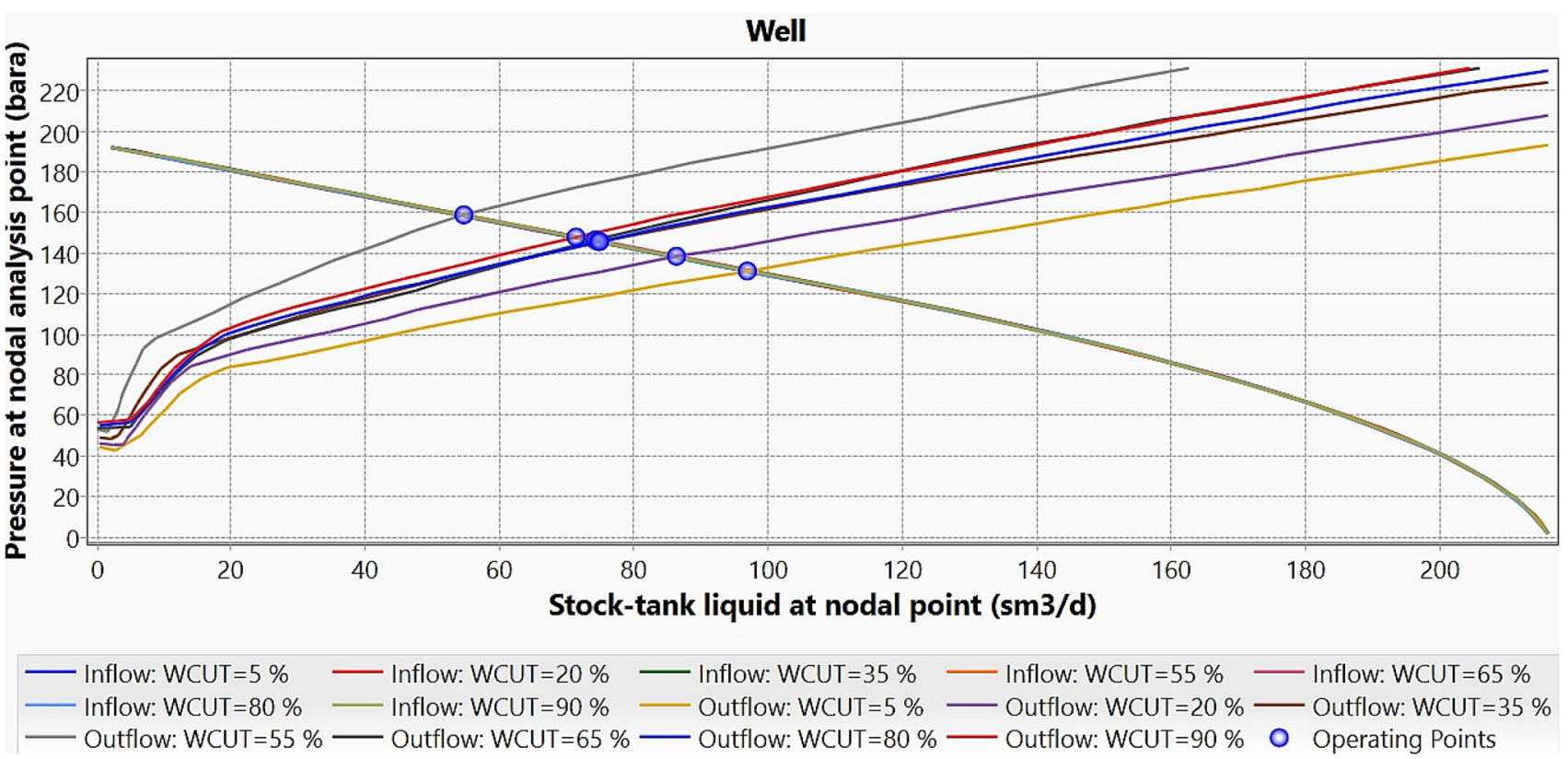

Fig. 3 The effect of an increase in water cut on the change in the liquid flow rate of the gas-lift well

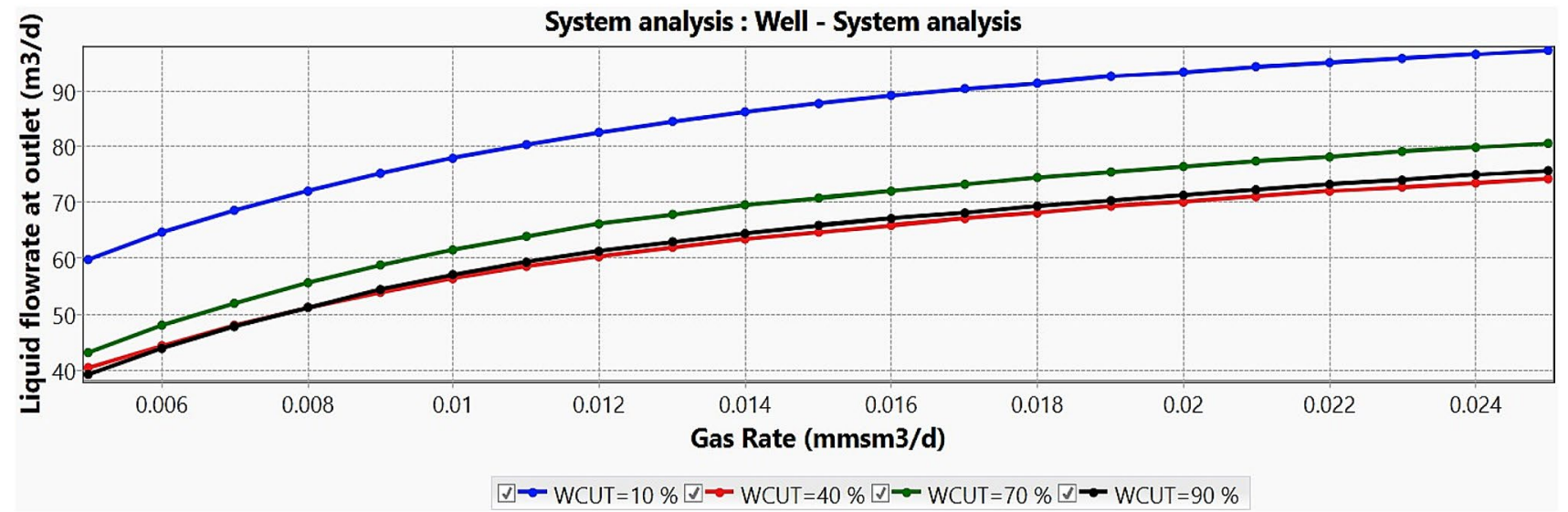

Fig. 4 Choosing the optimal operation regime of the gas-lift well

Table 7 Determination of optimal compressed gas injection rate for various water cuts

\begin{tabular}{lll}
\hline Water cut $(\%)$ & $\begin{array}{l}\text { Optimal gas injection } \\
\text { rate }\left(\mathrm{m}^{3} / \mathrm{d}\right)\end{array}$ & $\begin{array}{l}\text { Liquid flow } \\
\text { rate }\left(\mathrm{m}^{3} / \mathrm{d}\right)\end{array}$ \\
\hline 10 & 20,500 & 94.2 \\
40 & 21,500 & 71.9 \\
70 & 22,500 & 76.4 \\
90 & 23,500 & 74.1 \\
\hline
\end{tabular}

component composition, liquid flow rate and component composition of injected petroleum gas. In this paper, the pressure and flow temperature distribution curves are obtained from the analysis of the P-T profile in the PIPESIM program. The wax deposits start crystalizing when the temperature of the flow falls below the WAT, so the depth of the onset of wax formation corresponds to the intersection of the distribution of the flow temperature curve and the WAT curve obtained by using the developed algorithm (Fig. 5).

According to the results, by applying the compositional multiphase model, it is established that the depth corresponding to the onset of the formation of wax deposits in the gas-lift well is from 350 to $360 \mathrm{~m}$ from the wellhead 


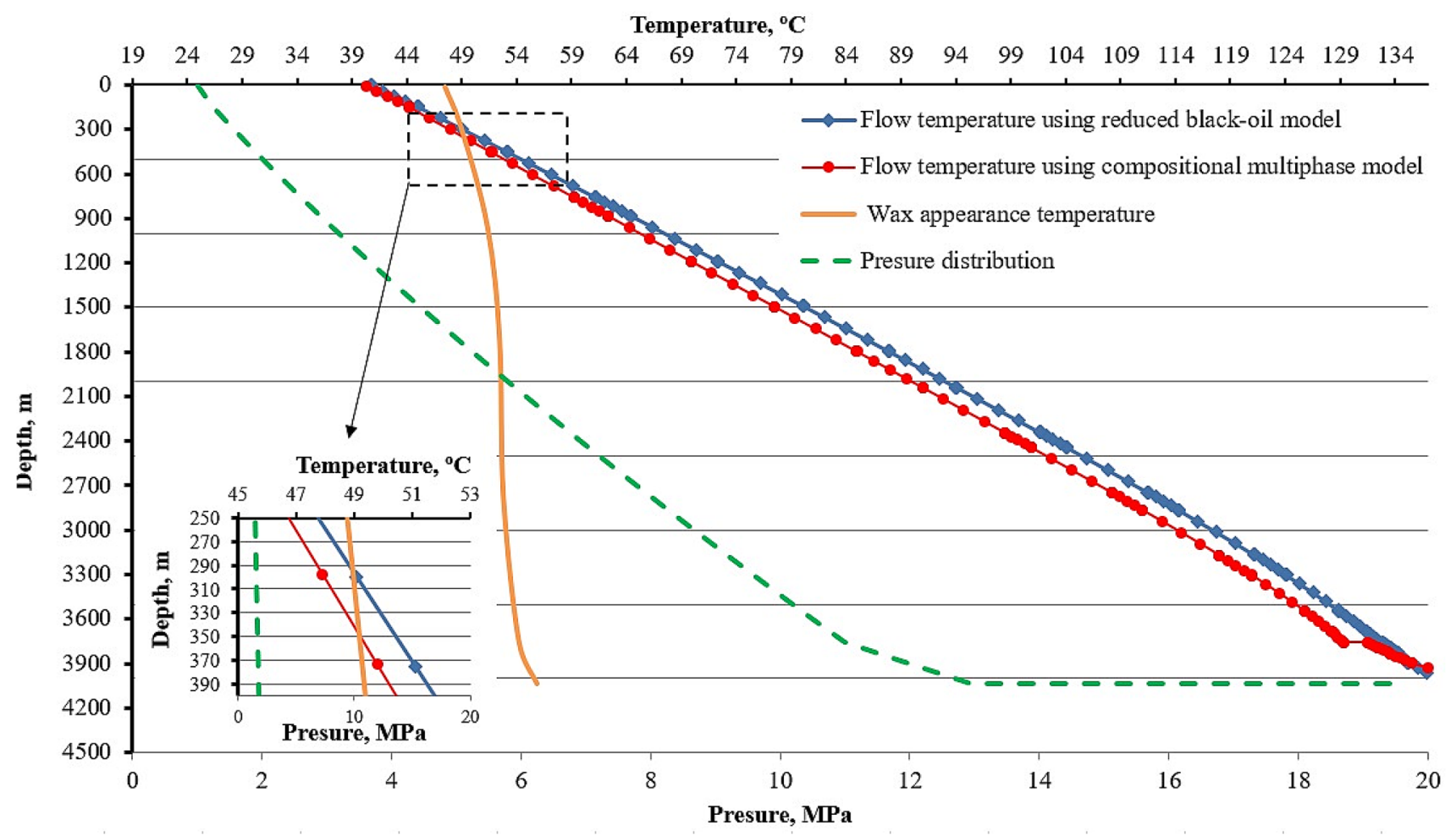

Fig. 5 Determination of wax formation depth in the gas-lift well

compared to $290-310 \mathrm{~m}$ which observed by using reduced black-oil model.

\section{Conclusions}

As a result of the study using the developed algorithm, taking into account the effect of the injected gas, it was observed that when the pressure decreases during the lifting of the fluid along the wellbore, the wax appearance temperature decreases.

The results from the modeling where the highly accurate compositional multiphase high-wax model was applied show that with an increase in water cut to the phase inversion point (in the range from 50 to $60 \%$ water cut), an increase in the viscosity of the oil-water emulsion is observed, leading to a decrease in the liquid flow rate of the gas-lift well. With a water cut of over $60 \%$, an increase in well production is obtained. The optimal well operation mode was determined by interpreting the well system analysis, which shows that the liquid flow rate of the well increases with an increase in the gas injection rate to a point after which the liquid flow rate of the well plateaus.

The results from determination the depth of wax formation by applying the compositional multiphase model show that the depth corresponding to the onset of the formation of wax deposits in the gas-lift well is from 350 to $360 \mathrm{~m}$ from the wellhead compared to $290-310 \mathrm{~m}$ which is observed by using the reduced black-oil model.

Acknowledgements We acknowledge Evgeny A. Kibirev, head of oil production technology, technology and methods of the oil production department (Gazpromneft-NTC LLC, Saint Petersburg, Russian Federation), for his assistance during the experiments. Finally, we would like to thank the Saint-Petersburg mining university (Saint-Petersburg, Russian Federation) for providing laboratory equipment, support and samples for this research.

Open Access This article is licensed under a Creative Commons Attribution 4.0 International License, which permits use, sharing, adaptation, distribution and reproduction in any medium or format, as long as you give appropriate credit to the original author(s) and the source, provide a link to the Creative Commons licence, and indicate if changes were made. The images or other third party material in this article are included in the article's Creative Commons licence, unless indicated otherwise in a credit line to the material. If material is not included in the article's Creative Commons licence and your intended use is not permitted by statutory regulation or exceeds the permitted use, you will need to obtain permission directly from the copyright holder. To view a copy of this licence, visit http://creativecommons.org/licenses/by/4.0/. 


\section{References}

Aleksandrov AN, Rogachev MK, Van TN, Kishchenko MA (2019) Simulation of organic solids formation process in high-wax. Top Issues Rational Use Nat Resour 2:779

Aslanov H, Novruzov A, Harun A (2019) Managing wax-deposition risks in oil subsea pipelines by integrating wax modeling and pigging performance. SPE Prod Oper 34(03):625-634. https:// doi.org/10.2118/194506-pa

Berne-Allen A Jr, Work LT (1938) Solubility of refined paraffin waxes in petroleum fractions. Ind Eng Chem 30(7):806-812. https://doi. org/10.1021/ie50343a019

Carroll JA (1990) Multivariate production systems optimization. Diss. Stanford University

Coutinho R, Williams W, Waltrich P, Mehdizadeh P, Scott S (2017, December) A model for liquid-assisted gas-lift unloading. In: 18th international conference on multiphase production technology. BHR Group

Decker K, Sutton RP (2018, August) Gas lift annulus pressure. In: SPE artificial lift conference and exhibition-Americas. Society of Petroleum Engineers. https://doi.org/10.2118/190929-ms

Drozdov AN, Gorbyleva YA (2019) Improving the operation of pumpejector systems at varying flow rates of associated petroleum gas. J Min Inst 238:415-422. https://doi.org/10.31897/PMI.2019.4.415

Du F, Nojabaei B, Johns RT (2018, September) A black-oil approach to model produced gas injection for enhanced recovery of conventional and unconventional reservoirs. In: SPE annual technical conference and exhibition. Society of Petroleum Engineers. https ://doi.org/10.2118/191454-ms

Fadairo ASA, Ameloko A, Ako CT, Duyilemi O (2010) Modeling of wax deposition during oil production using a two-phase flash calculation. Pet Coal 52(3):193-202

Feder J (2019) Gas lift operations require accurate predictions of downhole annulus pressure. J Petrol Technol 71(03):65-67. https://doi. org/10.2118/0319-0065-jpt

Fleyfel F, Meng W, Hernandez O (2004) Production of waxy low temperature wells with hot gas lift. In: SPE annual technical conference and exhibition. Society of Petroleum Engineers. https://doi. org/10.2118/89853-ms

Gabov VV, Zadkov DA, Nguyen KL (2019) Features of elementary burst formation during cutting coals and isotropic materials with reference cutting tool of mining machines. J Min Inst 236:153161. https://doi.org/10.31897/PMI.2019.2.153

Hansen JH et al (1988) A thermodynamic model for predicting wax formation in crude oils. AIChE J 34(12):1937-1942. https://doi. org/10.1002/aic.690341202

Lake LW, Kohse BF, Fanchi JR, Nghiem LX (2006) Petroleum engineering handbook: volume I general engineering. SPE, Texas, pp 397-453

Leontaritis KJ (1998) The wax deposition envelope of gas condensates. Offshore technology conference. Offshore technology conference. https://doi.org/10.4043/8776-ms

Lira-Galeana C, Firoozabadi A, Prausnitz JM (1996) Thermodynamics of wax precipitation in petroleum mixtures. AIChE J 42(1):239248. https://doi.org/10.1002/aic.690420120

Mahmudi M, Taghi Sadeghi M (2013) Performance analysis of compositional and modified black-oil models for a gas lift process.
Oil Gas Sci Technol 68(2):319-330. https://doi.org/10.2516/ ogst/2012001

Mydland S, Whitson CH, Carlsen ML, Dahouk MM, Yusra I (2020, July) Black-oil and compositional reservoir simulation of gasbased EOR in tight unconventional. In: SPE/AAPG/SEG unconventional resources technology conference. Unconventional resources technology conference. https://doi.org/10.15530/urtec $-2020-2765$

Pedersen KS, Fredenslund A, Thomassen P (1989) Properties of oils and natural gases, vol 5. Gulf Pub Co., p 385

Ravindran N, Horne RN (1993) Multivariate optimization of production systems: the time dimension. No. DOE/BC/14600-42; SUPRI-TR-90. Stanford University, CA (United States). Petroleum Research Inst. https://doi.org/10.2172/10146223

Rogachev MK, Strizhnev KV (2006) Bor'ba s oslozhneniyami pri dobyche nefti. [Fighting complications in oil production]. Nedra, p 296

Schou P, Karen PS, Hans PR (1991) Wax precipitation from North Sea crude oils. 4. Thermodynamic modeling. Energy Fuels 5(6):924-932

Sevic Snezana, Grubac Branko (2017) Simulation of temperaturepressure profiles and wax deposition in gas-lift wells. Chem Ind Chem Eng Quart 23(4):537-545. https://doi.org/10.2298/CICEQ $161014006 \mathrm{~S}$

Shedid SA, Yakoot MS (2016) Simulation study of technical and feasible gas lift performance. Int J Petrol Sci Technol 10(1):21-44

Weingarten JS, Euchner JA (1988) Methods for predicting wax precipitation and deposition. SPE Prod Eng 3(01):121-126. https:// doi.org/10.2118/15654-PA

White M, Pierce K, Acharya T (2018) A review of wax-formation/ mitigation technologies in the petroleum industry. SPE Prod Oper 33(03):476-485. https://doi.org/10.2118/189447-PA

Won KW (1986) Thermodynamics for solid solution-liquid-vapor equilibria: wax phase formation from heavy hydrocarbon mixtures. Fluid Phase Equilib 30:265-279. https://doi.org/10.1016/03783812(86)80061-9

Schumberger PIPESIM [Electronic resource]. http://www.sis.slb.ru/ pipesim/. Accessed 04/15/18

Zhao Y, Limb D, Zhu X (2017, December) A study of wax deposition in pipeline using thermal hydraulic model. In: 18th international conference on multiphase production technology. BHR Group

Zheng S, Saidoun M, Mateen K, Palermo T, Ren Y, Fogler HS (2016, May) Wax deposition modeling with considerations of non-newtonian fluid characteristics. In: Offshore technology conference. Offshore technology conference. https://doi.org/10.4043/26914-ms

Zheng S, Saidoun M, Palermo T, Mateen K, Fogler HS (2017) Wax deposition modeling with considerations of non-Newtonian characteristics: application on field-scale pipeline. Energy Fuels 31(5):5011-5023. https://doi.org/10.4043/26914-MS

Publisher's Note Springer Nature remains neutral with regard to jurisdictional claims in published maps and institutional affiliations. 